\title{
Reinforcement with geosynthetics of walls of the saltpans of the Aveiro Lagoon
}

\author{
Carlos, D.M., Department of Civil Engineering, University of Aveiro, Aveiro, \\ Portugal,dmc@ua.pt \\ Pinho-Lopes, Margarida, Department of Civil Engineering, University of Aveiro, \\ Aveiro, Portugal, mlopes@ua.pt
}

\begin{abstract}
The aim of this article is to investigate the solution for the reinforcement of the walls of the saltpans of the Aveiro lagoon by using geosynthetics. For that purpose literature research has been done to collect both the properties and the geometry of the walls and of the soils. Simultaneously, methods for the design of reinforced soils using geosynthetics were collected, particularly to allow the consideration of two types of backfill soil: granular and fine. So, two solutions for such walls were studied using granular and fine soils, respectively. The design methods used were the ones proposed by: Jewell (1996) and Rogbeck et al. (2002) for granular soils and Naughton et al. (2001) for fine soils. Finally, the verification of the external stability of the profiles of a selected wall has been made using the methodology described in Eurocode 7: EN1997-1: 2004.
\end{abstract}

\section{Keywords}

Design, Geosynthetics, Reinforcement, Fine soil, Walls of Aveiro lagoon.

\section{Introduction}

As natural heritage of the region, the Aveiro lagoon has allowed that, over time, people have lived in its periphery and developed many different activities (agricultural, fishing, commercial, industrial and tourism), which have resulted on social and human development of the region. However, these activities haven't always had the same importance. In fact, some of them are well present in the lagoon environment, while others have almost been abandoned. One of those cases of abandonment is the activity related to the production of salt in the Aveiro lagoon.

Actually, this is one of the catalysts for the present study, since the abandonment of the walls of saltpans is due to the extinction of this activity. 
The main objective of this work is the study of new solutions for the walls of the saltpans by using soil reinforcement, particularly with geosynthetics. The use of local soils is of particular interest. This will contribute for the reclassification of the hydrologic and environmental behaviour of Aveiro lagoon.

For that goal a generic profile of the wall was adopted and two different types of soils were considered: granular and fine. In addition to these steps, specialized literature on the reinforcement of walls with geosynthetics was used to establish the theoretical basis of the design of such structures. Finally, some considerations regarding the construction process, the corrective measures to promote the stability during construction and the measures for the environmental protection of the walls are included.

\section{CASES STUDIED}

\subsection{Wall geometry and soil properties}

The cases studied consist of the design of wall represented in Fig 1 using two types of soil: case A, for granular soil, and case B, for fine soils, as suggested in Table 1. The foundation is always composed by fine soil, which is the soil of the area of deployment of the saltpans. Two combinations of parameters for the characterization of fine soil, and consequently for the foundation soil, were considered (Combination $1-\mathrm{C} 1$ and Combination $2-\mathrm{C} 2$ ). The corresponding values were obtained from the literature research, by considering significant ranges of values for the soil properties, in order to achieve results that represent the study area widely.

Table 1 - Types of soils used in each case study.

\begin{tabular}{ccc}
\hline Case study & Wall soil & Foundation soil \\
\hline $\mathrm{A}_{\mathrm{C} 1}$ & Granular & Fine - Combination 1 \\
$\mathrm{A}_{\mathrm{C} 2}$ & Granular & Fine - Combination 2 \\
$\mathrm{B}_{\mathrm{C} 1}$ & Fine - Combination 1 & Fine - Combination 1 \\
$\mathrm{B}_{\mathrm{C} 2}$ & Fine - Combination 2 & Fine - Combination 2 \\
\hline
\end{tabular}

In Fig 1 the geometry of the wall, as well as the actions applied in it, are showed. These actions correspond to the water thrust (hydrostatic water pressure), and the surcharge associated with the service and construction of the wall. Details for its quantification can be found in Carlos (2009). 


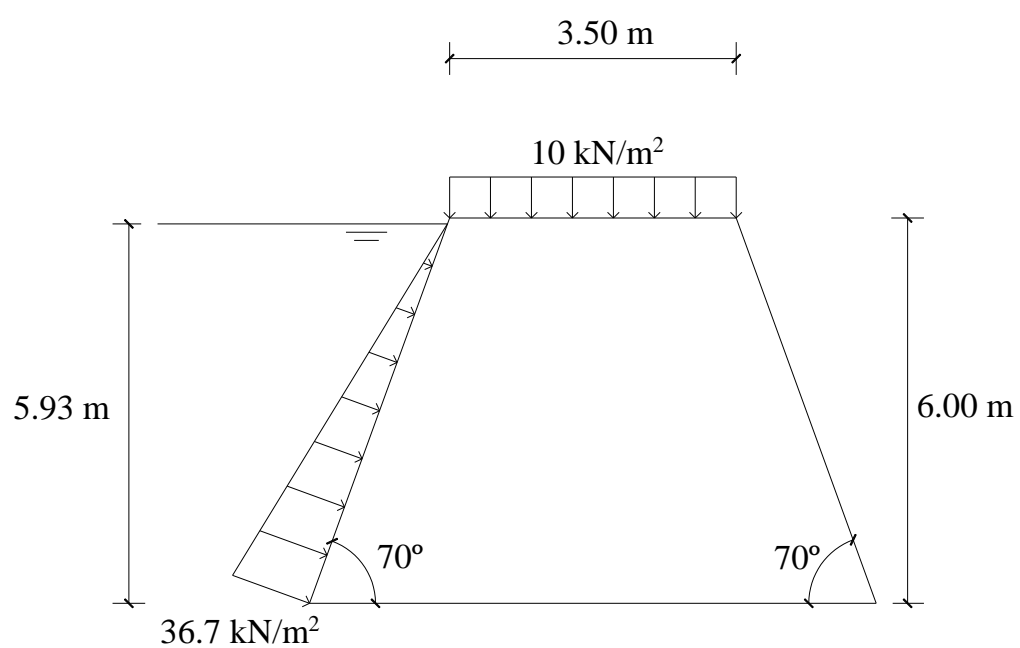

Fig 1- Profile of the wall considered.

The dimensions of the wall considered in this study were first analysed by Pereira and Coelho (2007). In this study the top level was determined corresponding to the maximum spring tide water level added to the wave run-up and to a security value due to overtopping and meteorological tides, related with low atmospheric pressures and persistent wind.

Similarly to what was done by Pereira and Coelho (2007), in the present study it has been considered that the hydrographic zero would correspond to the wall base. Such consideration is conservative and unlikely to occur, thus making the dimensions of the wall possibly exaggerated.

A literature research was carried out to obtain the identification and both physical and compressibility characteristics of the soil, using geotechnical studies on the relevant area. The geotechnical characterization of the area of the Aveiro lagoon was thoroughly studied at the beginning of the 90's of last century. This is documented in Gomes (1992) and includes a geotechnical zoning of the urban and suburban areas of Aveiro. The soils in these areas were also classified and some of their properties are presented by this author. From the zoning maps produced by Gomes (1992) results the classification of the soils in the saltpans areas of the Aveiro lagoon as Complex Alluvium Sludges (CAL).

More recently Bonito (2008) carried out an extended campaign of both laboratory and field tests to characterize the soils in the area of Aveiro. Some properties of the soils considered in this paper were determined using triaxial and field tests, published by Bonito (2008). 
Therefore, the soil characteristics considered are a combination of the parameters proposed by both Gomes (1992) and Bonito (2008) and are presented in Table 2. They are: the soil unit weight, $\gamma$; the soil friction angle in terms of effective stresses, $\phi^{\prime}$; the cohesion in terms of effective stresses, c'; the undrained strength, $\mathrm{c}_{\mathrm{u}}$; the coefficient of volume compressibility, $\mathrm{m}_{\mathrm{v}}$; and the coefficient of vertical consolidation, $\mathrm{c}_{\mathrm{v}}$.

In this work two combinations of values for the fine soil strength properties were considered.

Table 2 - Soils characteristics.

\begin{tabular}{ccccccc}
\hline Soil & $\gamma\left(\mathrm{kN} / \mathrm{m}^{3}\right)$ & $\phi^{\prime}\left({ }^{\circ}\right)$ & $\mathrm{c}^{\prime}(\mathrm{kPa})$ & $\mathrm{c}_{\mathrm{u}}(\mathrm{kPa})$ & $\mathrm{m}_{\mathrm{v}}\left(\times 10^{-4} \mathrm{kPa}^{-1}\right)$ & $\mathrm{c}_{\mathrm{v}}\left(\mathrm{m}^{2} /\right.$ year $)$ \\
\hline Granular & 18 & 33 & 0 & - & - & - \\
Fine-C1 & 16 & 34 & 7 & 25 & 4.13 & 5.2 \\
Fine-C2 & 16 & 20 & 27 & 15 & 4.13 & 5.2 \\
\hline
\end{tabular}

\subsection{Geosynthetics}

In this study four different geosynthetics were considered (Fig 2): two high density polyethylene extruded geogrids, GGR1 and GGR2, and two geocomposites reinforcement, GCR1 and GCR2.

Geogrids GGR1 and GGR2 are identical and differ mainly in their tensile properties. The geocomposite GCR1 is an association of a polypropylene needled punched nonwoven geotextile reinforced with polyester strands in the machine direction. The geocomposite GCR2 consists of a polyester core filament coated with polyethylene and drainage element in polyethylene nonwoven geotextile.

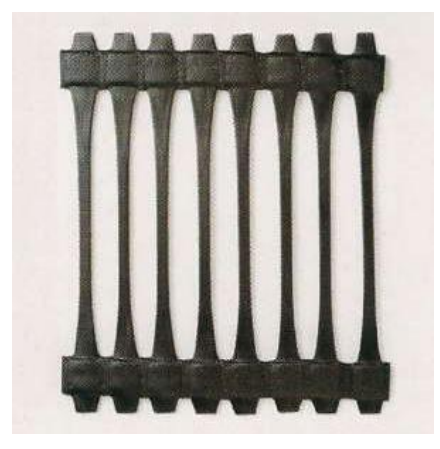

a)

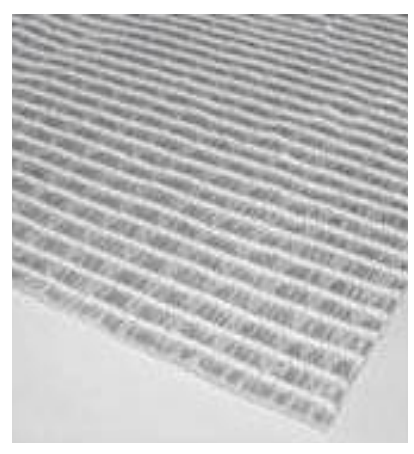

b)

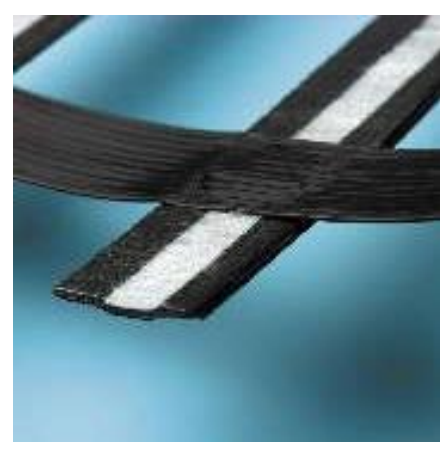

c)

Fig 2- Geosynthetics used in the design: a) Uniaxial Geogrid GGR1; b) Geocomposite GCR1; c) Geocomposite GCR2. 
Some properties of the geosynthetics are identified in Table 3. The values of the ultimate tensile strength of the materials, $F_{u l t}$, and of their transmissivity are the ones included in the manufacturers' specifications. The other two properties in this table are: $F_{c J}$, design tensile strength obtained by the method of Jewell (1996); and $\mathrm{F}_{\mathrm{cNH}}$, design tensile strength obtained by the method of the Nordic Handbook (NH), presented by Rogbeck et al. (2002). These quantities result from the Equations 1 and 2, respectively. The transmissivity $(\theta)$ of the geocomposites is also included.

Table 3- Parameters of the geosynthetics used for internal design methods.

\begin{tabular}{ccccc}
\hline \multirow{2}{*}{ Properties } & \multicolumn{4}{c}{ Geosynthetics } \\
\cline { 2 - 5 } & Geogrid & Geogrid & Geocomposite & Geocomposite \\
& GGR1 & GGR2 & GCR1 & GCR2 \\
\hline \multirow{2}{*}{ Function } & Reinforcement & Reinforcement & Reinforcement & Reinforcement \\
and draining & and draining \\
$F_{\text {ult }}(\mathrm{kN} / \mathrm{m})$ & 55.0 & 80.0 & 75.0 & 80 \\
$\mathrm{~F}_{\mathrm{cJ}}(\mathrm{kN} / \mathrm{m})$ & 11.5 & 16.7 & 8.1 & 27.9 \\
$\mathrm{~F}_{\mathrm{cNH}}(\mathrm{kN} / \mathrm{m})$ & - & 12.1 & 11.3 & - \\
$\theta\left(\times 10^{-7} \mathrm{~m}^{2} / \mathrm{s}\right)$ & - & - & 20.0 & 5.3 \\
\hline
\end{tabular}

$\mathrm{F}_{\mathrm{cJ}}=\frac{\mathrm{F}_{\mathrm{k}}}{\mathrm{RF}_{\mathrm{DDI}} \times \mathrm{RF}_{\mathrm{ATM}} \times \mathrm{RF}_{\mathrm{CR}}}$

$\mathrm{F}_{\mathrm{cNH}}=\frac{\eta_{1} \times \eta_{2} \times \eta_{3} \times \mathrm{F}_{\mathrm{k}}}{\gamma_{\mathrm{M}}}$

In these equations: $F_{k}$, is the characteristic tensile strength of the reinforcements; RFDDI, is the reduction factor for damage during installation in situ; $\mathrm{RF}_{\mathrm{ATM}}$, is the reduction factor for atmospheric effects; RFFLU, is the reduction factor for the effects of creep in the reinforcement; $\eta_{1}$, is the conversion factor for creep; $\eta_{2}$, is the conversion factor for the installation damage; $\eta_{3}$, is the conversion factor for the biological and chemical degradation; and $\gamma_{\mathrm{M}}$, is the partial safety factor for the soil parameters (equal to 1.0).

It should be pointed out that the method of Jewell uses the methodology recommended internationally (ISO/TR 20432:2007) by representing the agents and mechanisms affecting the durability of the geosynthetics using reduction factors (with a minimum value of 1.0). To better compare the values recommended by the two methods, in Table 4 the values of the factors used in both methods are presented (obtained from Jewell (1996) and Rogbeck et al. (2002)). 
Table 4 - Factors used to represent the effects of the agents and mechanisms affecting the durability of the geosynthetics considered.

\begin{tabular}{|c|c|c|c|c|}
\hline \multirow[b]{2}{*}{$\begin{array}{c}\text { Factors } \\
\text { used }\end{array}$} & \multicolumn{4}{|c|}{ Geosynthetics } \\
\hline & $\begin{array}{c}\text { Geogrid } \\
\text { GGR1 }\end{array}$ & $\begin{array}{c}\text { Geogrid } \\
\text { GGR2 }\end{array}$ & $\begin{array}{c}\text { Geocomposite } \\
\text { GCR1 }\end{array}$ & $\begin{array}{c}\text { Geocomposite } \\
\text { GCR2 }\end{array}$ \\
\hline \multicolumn{5}{|c|}{ Partial safety factors for Jewell method } \\
\hline $\mathrm{RF}_{\mathrm{DDI}}$ & 1.05 & 1.05 & 1.05 & 1.05 \\
\hline $\mathrm{RF}_{\mathrm{ATM}}$ & 1.05 & 1.05 & 1.67 & 1.05 \\
\hline $\mathrm{RF}_{\mathrm{CR}}$ & 2.60 & 2.60 & 2.60 & 2.60 \\
\hline \multicolumn{5}{|c|}{ Conversion factors for $\mathrm{NH}$ method } \\
\hline$\eta_{1}$ & - & 0.20 & 0.20 & - \\
\hline$\eta_{2}$ & - & 0.83 & 0.83 & - \\
\hline$\eta_{3}$ & - & 0.91 & 0.91 & - \\
\hline
\end{tabular}

To better compare such values, in Table 5 they are presented in comparable terms, for the geosynthetics used with the two design methods (GGR2 and GCR1). The total reduction factor $\left(\mathrm{RF}_{\text {total }}\right)$ is the product of the relevant partial reduction factors ( $\eta$ for $\mathrm{NH}$ and $\mathrm{RF}$ for Jewell).

By analysing Table 5 it becomes clear that, for both GGR2 and GCR1, the $\mathrm{NH}$ method is more conservative, as the total reduction factor $\left(\mathrm{RF}_{\text {total }}\right)$ is higher than for the method of Jewell. For GGR2 the value for the NH method is $130 \%$ higher than for the method of Jewell, while for GCR1 such difference is of $45 \%$.

Such differences increase when the partial safety factor for the parameters of the soil $\left(\gamma_{\mathrm{M}}\right)$ is considered, as necessary for the application of the $\mathrm{NH}$ method.

Table 5 - Comparison of the reduction factors used to represent the effects of the agents and mechanisms affecting the durability of the geosynthetics considered.

\begin{tabular}{cccccc}
\hline Geosynthetic & \multicolumn{3}{c}{ GGR2 } & NH & Jewell \\
\hline Method & $\mathrm{NH}$ & $\mathrm{NH}$ & Jewell & $1 / \eta$ & $\mathrm{RF}$ \\
Agent & $\eta$ & $1 / \eta$ & $\mathrm{RF}$ & 5.00 & 2.60 \\
CR & 0.20 & 5.00 & 2.60 & 1.20 & 1.05 \\
DDI & 0.83 & 1.20 & 1.05 & 1.10 & 1.67 \\
BIO+CHE / ATM & 0.91 & 1.10 & 1.05 & 6.60 & 4.56 \\
\hline RF $_{\text {total }}$ & & 6.60 & 2.87 &
\end{tabular}

$\mathrm{CR}$ - creep; DDI - damage during installation; $\mathrm{BIO}+\mathrm{CHE}$ - biological and chemical degradation; ATM - atmospheric effects. 


\section{DESIGN APPROCHES}

\subsection{General remarks}

Internationally, some of the most important standards for the design of reinforced soil structures are: 1) the documents of the Federal Highway Administration, FHWA (USA); 2) the standards from the American Association of State Highway and Transportation Officials, AASHTO; 3) the English standard, UK BS8006-1 2009; and 4) the DIN 1054:2005-01 from Germany (Corbet and Horgan, 2010). The AASHTO and FHWA manuals were written as complimentary documents. The AASHTO documents are written as specifications, while the FHWA manual is a complete design and construction document. These documents often refer to each other (Christopher, 2010). Some of these documents written by both American organizations are: Elias et al. (2001); Berg et al. (2009); AASHTO (2002) and AASHTO (2007).

These standards define procedures and provide guidance for the completion of the internal design and the verification of the external stability of reinforced soil structures. The relevant internal and external failure mechanisms must be defined, and the safety and the reduction factors to consider for both materials and loads must be assessed.

For example, in the American standards the process of sizing and designing to preclude internal failure consists of determining the maximum developed tension forces, their location along a locus of critical slip surface and the resistance provided by the reinforcements both in pullout capacity and tensile strength. For external stability, these rules provide the verification of the following failure mechanisms: sliding on the base; limiting the location of the resultant of all forces (overturning); bearing capacity; and deep seated stability (rotational slip-surface or slip along a plane of weakness) (Elias et al. 2001).

With regard to the British standard UK BS8006-1: 2009, it is based on the philosophy of limit states for the design of reinforced soil walls, involving the increase of loads and the reduction of soil resistance and reinforcements, through the application of partial safety factors. Analyzing the internal stability, this standard considers that there must be stability with respect to rupture by traction of reinforcement, security to rupture by pullout, and stability of wedges of potential rupture in the reinforced landfill. For the external stability, the safety for 
the bearing resistance failure together with the failure by toppling, for the failure by sliding at the base, and for the overall stability should be checked.

It is difficult to make some comments regarding the German standard DIN 1054:2005-01, due to the language barrier (the document is written in German).

In addition to the methodologies described in these standards, there are several methods for performing a separate, internal design, and the establishment of guidelines to be used for verification of the external stability of the structure. Among the internal design methods that can be referred are, for example, the " $k$ stiffness" method proposed by Allen and Bathurst (2003), the method of the Nordic Handbook proposed by Rogbeck et al. (2002), the method of Jewell (1996), and the method of Naughton et al. (2001), among others. For the external stability the European standard EN 1997-1: 2004 can be used.

However, most of the rules and procedures referred include only the reinforcement of soils with good mechanical properties, i.e., soil free of, or with very little, cohesion and high friction angles. Beyond this, there are also restrictions on their use related to the soil-reinforcement interaction parameters, i.e., without the knowledge of these parameters it is not possible to use most of these standards or design methods. Thus, to quantify them it is necessary to conduct tests for characterization of the soil-reinforcement interface or, though less reliable, to use results from other studies. Some examples of such studies are documented by: Bergado et al. (1993); Athanasopoulos (1996); Chang et al. (1996); O'Kelly and Naughton (2008); Sieira et al. (2009); and Yin et al. (2008) for fine soils; and Liu et al. (2009); Fleming et al. (2006); Khedkar and Mandal (2009); and Pitanga et al. (2009) for granular soils.

\subsection{Internal design}

The internal design of a reinforced soil wall consists of the design of the reinforcements, which, in this case, are geosynthetics, by defining the minimum values of the tensile strength, length and spacing.

The type of soil used to build the wall determinates the design method to be used. Therefore, for the design of the reinforcements were used the following methods: Jewell (1996) and Nordic Handbook (here designated by $\mathrm{NH}$ ), documented by Rogbeck et al. (2002), both for granular soils; and Jewell (1996) and Naughton et al. (2001) for fine soils. 
The choice of these methods, in detriment of others commonly used internationally, is related to the restriction of using granular soils in some of those methods or to the lack of knowledge of the soil-reinforcement interaction strength in this study (it was not possible to carry out such tests and values for similar conditions could not be found).

It was decided to use two design methods for each type of soil to allow a more comprehensive discussion of the results, since they include slightly different approaches to the design. Also, it is important to mention that the method presented by Jewell (1996) does not take into account the singularities of the behaviour of fine soil (as it was developed for granular soils only). However, it was used in this study. On one hand, for the preliminary design of the reinforcements and, on the other hand, to enable the comparison between the values obtained by this method (typically for granular soils) with the results of the method of Naughton et al. (2001), specifically developed for fine soil.

The method of Jewell is well known. The method of NH is similar to many other used internationally. Thus, only the method of Naughton et al. (2001) is described in some detail in this paper.

The method of Naughton et al. (2001) was developed for a particular geosynthetic (from the family of products of GCR2), and refers to the use of unconventional materials as fill soils. This method is based on an iterative process where the time of dissipation of excess interstitial pressure and the transmissivity of the reinforcement used are checked. The process is schematically described in Fig 3.

Initially it is necessary to consider one value for the vertical spacing of the reinforcements. Such quantity is limited to a maximum of $0.5 \mathrm{~m}$ (Naughton et al. 2001).

Then, the calculation of the time required to dissipate the excesses of interstitial pressure generated $(\mathrm{T})$ is done. For such calculation, the dissipation tests conducted by Kempton et al. (2000) suggest the use of Equation 3 where, $\mathrm{F}_{\mathrm{Diss}}$ is the safety factor applied to the time of dissipation, $\mathrm{C}$ is a constant and $\mathrm{c}_{\mathrm{v}}$ is the coefficient of vertical consolidation of the soil. 


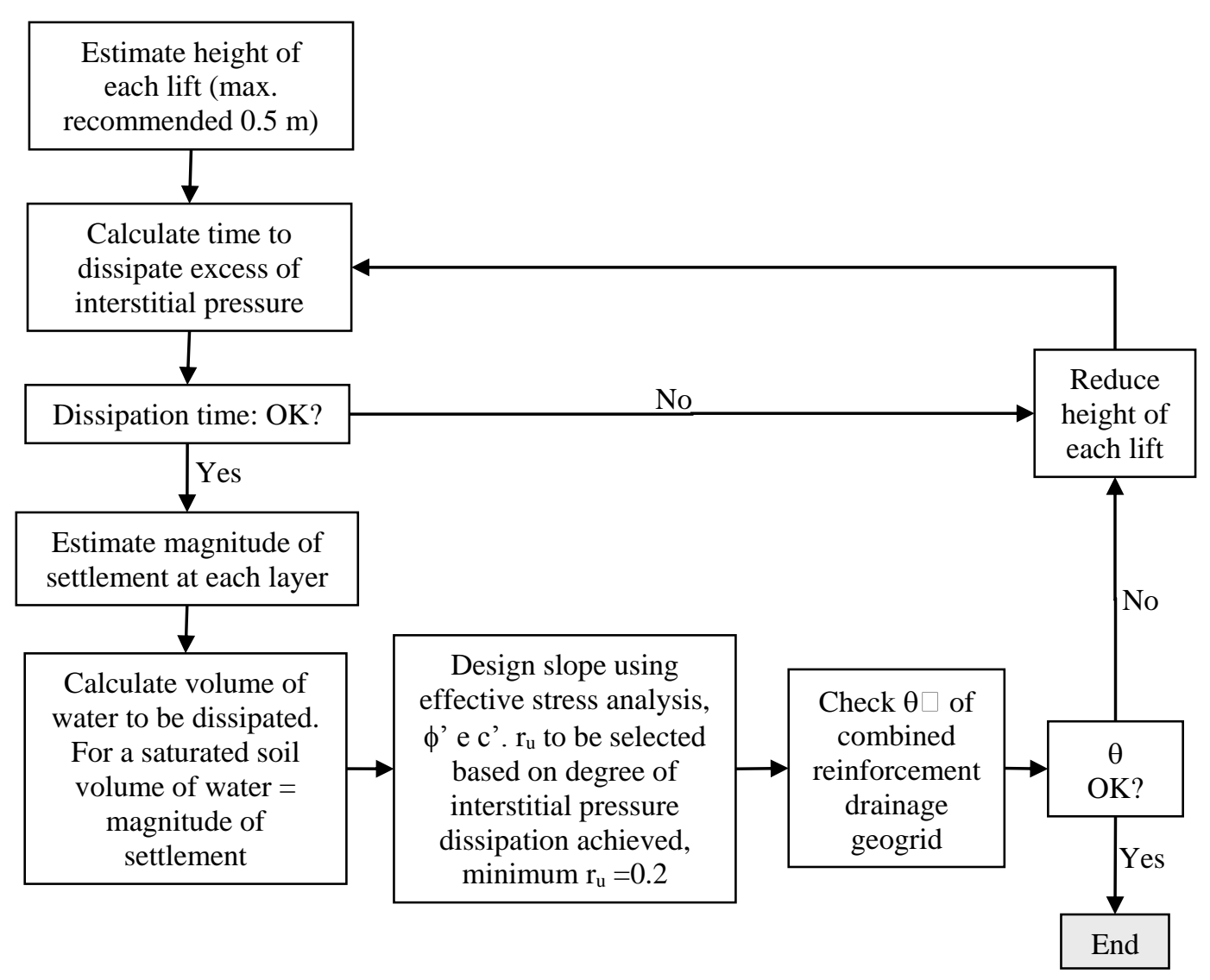

Fig 3 - Flow chart of design method (adapted from Naughton et al. (2001)).

The constant $\mathrm{C}$ was determined experimentally for the family of products of GCR2. The values obtained by Naughton et al. (2001) range between 0 and 470 and can be determined by an abacus (Fig 4).

Naughton et al. (2001) recommend that the safety factor is $F_{D i s s}=2.0$. This value takes into account the uncertainties in determining of $c_{v}$, the variability of cohesive soil and the extrapolations used in the tests for obtaining the equation.

$$
\mathrm{T}=\frac{\mathrm{F}_{\text {Diss }} \times \mathrm{C}}{\mathrm{c}_{\mathrm{v}}}
$$

The value of the interstitial pressure generated by the construction of an embankment layer on a pre-existing layer, $E_{p w p}$, is given by Equation 4, where $\mathrm{h}$ is the height of each layer, $\gamma$ is the unit weight of the soil used, $n$ is the number of layers constructed. The interstitial pressure parameter, $r_{u}$, is defined in Equation 5, where $\mathrm{u}$ is the interstitial pressure and $\mathrm{z}$ is the depth measured from the top of the wall to a point in study.

$$
\mathrm{E}_{\mathrm{pwp}}=\mathrm{h} \times \gamma+(\mathrm{n}-1)\left(\gamma \times \mathrm{h} \times \mathrm{r}_{\mathrm{u}}\right)
$$




$$
\mathrm{r}_{\mathrm{u}}=\frac{\mathrm{u}}{\gamma \times \mathrm{z}}
$$

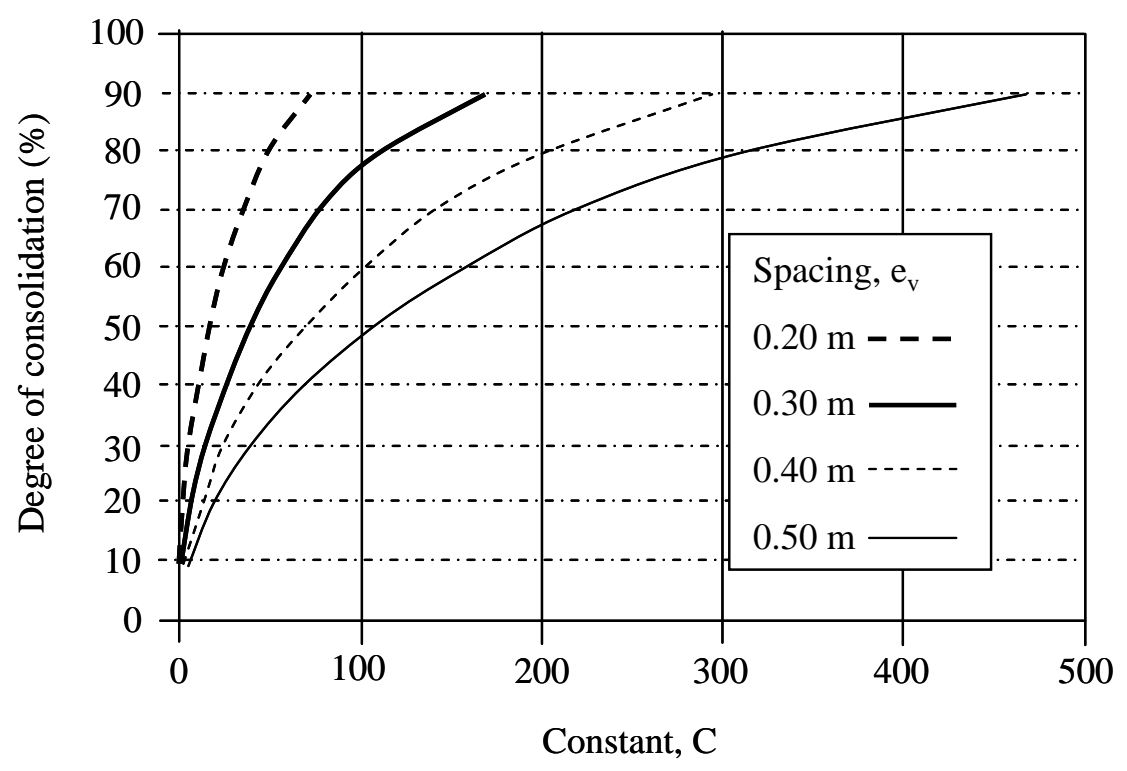

Fig 4 - Graph to obtain the constant C (adapted from Naughton et al. (2001)).

Naughton et al. (2001) also report that the degree of consolidation desirable to achieve before the construction of the next layer is $80 \%$ and that if the time of dissipation of excess interstitial pressure is not feasible, the spacing between reinforcement layers should be reduced and the new corresponding time of dissipation should be calculated.

The subsequent step is to calculate the vertical settlement and the water volume dissipated in each layer. The settlement, $\delta_{\mathrm{v}}$, is obtained by Equation 6 , where $m_{v}$ is the coefficient of volume compressibility and qQ the surcharge caused by the construction process.

$$
\delta_{\mathrm{v}}=\mathrm{m}_{\mathrm{v}} \times \mathrm{h} \times\left(\gamma \times \mathrm{h}+\mathrm{q}_{\mathrm{Q}}\right)
$$

If the degree of saturation of the soil exceeds $90 \%$, the volume of water dissipated can be calculated using the magnitude of the vertical settlement per unit area (Equation 7), where $\mathrm{V}$ is the volume of water (in liters) that comes out of the soil and $\delta_{\mathrm{v}}$ is the settlement of the layer, in meters (Naughton et al. 2001).

$$
\mathrm{V}=\delta_{\mathrm{v}} \times 1000
$$

In this method, proposals for the values of some parameters to be used in the analysis are also included. In fact, the minimum value of $r_{u}$ recommended is 0.2 
and corresponds to the degree of consolidation of $80 \%$ (mentioned as desirable for the design). The soil-reinforcement interaction coefficient can be obtained through the literature on this design method or by carrying out shear tests performed on the soil to be used in the structure (Naughton et al. 2001). It should be noted that, when geogrids are used such test may not be fully representative of the phenomena occurring and it is important to also carry out pullout tests.

Finally the transmissivity of the geosynthetics to be used has to be verified, to guarantee if it is sufficient to achieve a degree of consolidation of $80 \%$. According to Kempton et al. (2000), the value of this property of the geosynthetic has to be compared with the value of the required transmissivity, calculated from the volume of water dissipated (V) and the time necessary for consolidation (T) using Equation 8.

$$
\theta=\frac{\mathrm{V}}{\mathrm{T}}
$$

This property must be checked twice. First, right after the construction of each layer, when the hydraulic gradient is high, but the confining stress is low. Secondly, when the construction is completed and the hydraulic gradient is reduced but the confining stress is high. If the transmissivity of the geosynthetics is insufficient, the spacing between reinforcements has to be reduced and the process repeated (Naughton et al. 2001).

The information regarding the determination of the length of the reinforcement, $L_{R}$, is not available in Naughton et al. (2001). Naughton (2009) refers that $L_{R}$ should be obtained from Equation 9, being $H$ the height of the wall and $\phi^{\prime}$ the soil friction angle in terms of effective stresses.

$$
\left\{\begin{array}{l}
\mathrm{L}_{\mathrm{R}}=0.7 \times \mathrm{H} \Leftarrow \phi^{\prime}=30^{\circ} \\
\mathrm{L}_{\mathrm{R}}=1.1 \times \mathrm{H} \Leftarrow \phi^{\prime}=22^{\circ}
\end{array}\right.
$$

Some examples of application of this method were presented by Naughton et al. (2001) and Clancy and Naughton (2008). In the present paper a design example carried out by Naughton et al. (2001) is briefly described as it is, in some aspects, comparable to the current case. In fact, it refers to the design of a slope with dimensions and soil properties approximate to those considered in many of the cases studied in this paper, allowing comparisons between the results obtained (see section 4.1). 
The slope designed by Naughton et al. (2001) had an angle with the horizontal of $70^{\circ}$ and a height of $5 \mathrm{~m}$; the compressibility characteristics of the soil are present in Table 6 and the soil unit weight was $18 \mathrm{kN} / \mathrm{m}^{3}$; the vertical spacing between layers considered was $0.5 \mathrm{~m}$ (Naughton et al. 2001).

Table 6 - Compressibility characteristics of a design example (adapted from Naughton et al. (2001)).

\begin{tabular}{cccc}
\hline Confining stress $(\mathrm{kPa})$ & $0-40$ & $40-75$ & $75-100$ \\
\hline $\mathrm{c}_{\mathrm{v}}\left(\mathrm{m}^{2} /\right.$ year $)$ & 10 & 8 & 6 \\
$\mathrm{~m}_{\mathrm{v}}\left(\times 10^{-4} \mathrm{kPa}^{-1}\right)$ & 5 & 4 & 3 \\
\hline
\end{tabular}

The results obtained by these authors are shown in Table 7 and demonstrate that, for this example, the longest period required for the dissipation of the interstitial pressure is 103 hours, the maximum vertical settlement is scheduled to happen in the layers 7 to 10 and corresponds to $2.25 \mathrm{~mm}$, the calculated total vertical settlement is $18.9 \mathrm{~mm}$ and the maximum transmissivity required for the geosynthetic is equal to $0.1 \times 10^{-7} \mathrm{~m}^{2} / \mathrm{s}$ (Naughton et al. 2001).

Table 7 - Results obtained in a design example of Naughton et al. (2001).

\begin{tabular}{ccccccccccc}
\hline Layer & 1 & 2 & 3 & 4 & 5 & 6 & 7 & 8 & 9 & 10 \\
\hline $\begin{array}{c}\text { Height of } \\
\text { slope (m) }\end{array}$ & 0.5 & 1.0 & 1.5 & 2.0 & 2.5 & 3.0 & 3.5 & 4.0 & 4.5 & 5.0 \\
$\begin{array}{c}\text { Confining } \\
\text { stress (kPa) }\end{array}$ & 90 & 81 & 72 & 63 & 54 & 45 & 36 & 27 & 18 & 9 \\
$\mathrm{~T}(\mathrm{hr})$ & 103 & 103 & 77.6 & 77.6 & 77.6 & 77.6 & 62.1 & 62.1 & 62.1 & 62.1 \\
$\begin{array}{c}\delta_{\mathrm{v}}(\mathrm{mm}) \\
\theta\left(\times 10^{-7}\right.\end{array}$ & 1,35 & 1.35 & 1.80 & 1.80 & 1.80 & 1.80 & 2.25 & 2.25 & 2.25 & 2.25 \\
$\left.\mathrm{~m}^{2} / \mathrm{s}\right)$ & 0.04 & 0.04 & 0.06 & 0.06 & 0.06 & 0.06 & 0.1 & 0.1 & 0.1 & 0.1 \\
\hline
\end{tabular}

\subsection{Verification of external stability}

Regarding the verification of the external stability of the profiles studied, the following failure mechanisms were considered: failure by toppling, failure by sliding at the base, bearing resistance failure and loss of overall stability.

Among the various failure mechanisms included in EN 1997-1: 2004, only those relevant to this study were considered. More, the chosen mechanisms have different degree of importance. For these structures, a failure by toppling is expected, since these are structures with sloped faces and width substantially greater than their height. 
For the other failure mechanisms, it is more difficult to ensure they will not occur. On the one hand, the mobilization of resistance on the foundation is low, since, in all cases considered, the foundation soil is always a fine and saturated soil. This may result in failure by sliding at the base. On the other hand, for the cases studied in which the soil of the wall is fine, the development of excesses of interstitial pressures during the construction period can compromise the global stability and the bearing resistance of foundation soil. Thus, this period is crucial to ensure that these mechanisms do not occur.

In addition to these mechanisms, the verification of water seepage into the structure and hence the emergence of the piping phenomenon is another relevant mechanism. For the solutions using granular soils, the presence of surface erosion control and lining systems was assumed. For the solutions using fine soils, it was considered that the fill material would guarantee low permeability and a surface erosion control system was also included. The assumption of stability was based on these measures. Such stability analyses were not carried out in the present work.

For all the solutions considered the wall foundation soil is fine, thus it is necessary to carry out two types of analysis for the external stability: one for the conditions immediately after the wall construction (analyses in total stresses) and another for the long-term conditions (analyses in effective stresses).

The performance of the wall as a protection to the saltpans, particularly during the tide cycles, implies low permeability. Therefore, the measures mentioned before are quite relevant.

The design approach suggested in EN 1997-1: 2004 (limit state EQU - loss of equilibrium of the structure or the ground) was used to study the failure by toppling.

The limit states GEO (collapse or excessive deformation of the ground) and STR (internal collapse or excessive deformation of the structure or structural elements) of EN 1997-1: 2004 were used to study the sliding at the base and the bearing capacity of the structure.

The overall stability was analyzed by using commercial software: Slope/W of GeoSlope (version 2007). An overall safety factor was used to reduce the number of cases to be studied. A minimum value of 1.5 was considered. In such analyses, the water level was assumed to be at the top of the wall. In the most critical 
structure analysed, with a height of $5.93 \mathrm{~m}$, the slope determinant for the stability is the one on the saltpan side (not subjected to the hydrostatic pressure). The seepage forces were not taken into consideration.

The reinforcements were considered along the complete wall width, for each reinforcement level. The soil-reinforcement interaction coefficients used were the ones resulting from the method of Jewell (1996). The effect of geosynthetic used on the face of the slope of the structure was not considered.

For analyses in effective stresses the Mohr-Coulomb model was used to represent the behaviour soil. On the other hand, for analyses in total stresses the model for the behaviour of soil used is the undrained.

It was also considered that the dimensions of the layer of the foundation soil (width and depth) used in the model were sufficient to not influence the factors of safety obtained (the slips surfaces obtained indicate that this assumption is true).

The use of such software has some limitations, resulting from both the assumptions described before and the operating process. Slope/W uses the geotechnical limit equilibrium stability analysis. However, this analysis has limitations, which arise principally because the method does not consider strain and displacement compatibility. This has two serious consequences. One is that local variations in safety factors cannot be considered, and the second is that the computed stress distributions are often unrealistic. Fortunately it does not mean the overall factor of safety is necessarily unacceptable just because some unrealistic stresses exist for some slices. Thus, is necessary to take very careful and caution when stress concentrations exist in the potential sliding mass due to the slip surface shape or due to soil-structure interaction (SLOPE/W, 2007).

However, [although it has not been used] one way to obtain stress distribution realistically and reduce the limitations of the limit equilibrium stability analysis is use finite element computed stresses instead of determining the stresses from equations of statics (SLOPE/W, 2007).

Inherent in limit equilibrium stability analyses is the requirement to analyze many trial slip surfaces and find the slip surface that gives the lowest factor of safety. Recent research has shown that assumed user-specified slip surface shapes do not necessarily give the lowest possible factor of safety. This is another limitation of the limit equilibrium stability analysis used for Slope/W. Algorithms that alter the slip surface shape in some systematic manner tend to give lower 
safety factors than for a predetermined slip surface shape. For example, say a minimum factor of safety has been found for a circular slip surface. Further refinement of the shape can lead to a non-circular slip surface with a lower factor of safety. In Slope/W this is called optimization, auto-search or auto location of the slip surface shape and position (SLOPE/W, 2007). This technique is not used in this study.

Thus, a full understanding of the method and its limits leads to greater confidence in the use and in the interpretation of the results. In order to obtain this level of understanding, it is important to look at more than just the factor of safety. To use the limit equilibrium method effectively, it is also important to examine the detailed slice forces and the variation of parameters along the slip surface during the course of a project (SLOPE/W, 2007).

Finally, it is extremely important to recognize that stress-strain behavior of the structure in situ is highly dependent on the procedures and construction details (SLOPE/W, 2007). This effect was not considered for this software.

\section{PRESENTATION AND DISCUSSION OF RESULTS}

\subsection{Internal design}

The results obtained for the internal design vary with several factors. Among these, the calculation method, the type of soil used as fill material, the type of geosynthetics used as reinforcement and the existence of water in the soil can be pointed out.

The results obtained from the internal design are presented in Table 8, for granular soils, and in Table 9, for fine soils. In those tables a comparison, in percentage, of the most relevant parameters obtained is also included.

The discussion of results is done only for the methods considered in this work. The authors had difficulties in finding other works with sufficient detail that would allow such comparison.

For the use of granular soils, it is found that, as expected, LR obtained through the two methods considered is different since the methods of design have different approaches. In fact, the method of Jewell leads to an equal reinforcement length to 
be used in all the height of the wall. For the method of $\mathrm{NH}$ the length of the reinforcement is variable with the height of the wall.

Table 8 - Results obtained by the methods of internal design - granular soils.

\begin{tabular}{|c|c|c|c|c|c|c|}
\hline \multirow{2}{*}{ Case study } & \multirow{2}{*}{ Geosynthetics } & \multirow{2}{*}{$\mathrm{z}(\mathrm{m})$} & \multirow{2}{*}{ Parameter } & \multicolumn{2}{|c|}{ Design method } & \multirow{2}{*}{$\begin{array}{l}\text { PPR1 } \\
(\%)\end{array}$} \\
\hline & & & & Jewell & $\mathrm{NH}$ & \\
\hline \multirow{4}{*}{$\begin{array}{c}\text { A } \\
\text { Sol } 1(\mathrm{~J})\end{array}$} & \multirow{2}{*}{ GGR2 } & \multirow{2}{*}{$3<z<6$} & $\mathrm{e}_{\mathrm{v}}(\mathrm{m})$ & 0.5 & - & - \\
\hline & & & $\mathrm{L}_{\mathrm{R}}(\mathrm{m})$ & 2.95 & - & - \\
\hline & \multirow{2}{*}{ GGR1 } & \multirow{2}{*}{$0<z<3$} & $\mathrm{e}_{\mathrm{v}}(\mathrm{m})$ & 0.6 & - & - \\
\hline & & & $\mathrm{L}_{\mathrm{R}}(\mathrm{m})$ & 2.95 & - & - \\
\hline \multirow{4}{*}{$\begin{array}{c}\text { A } \\
\text { Sol } 1(\mathrm{NH})\end{array}$} & \multirow{4}{*}{ GGR2 } & \multirow{2}{*}{$3<z<6$} & $\mathrm{e}_{\mathrm{v}}(\mathrm{m})$ & - & 0.3 & - \\
\hline & & & $\mathrm{L}_{\mathrm{R}}(\mathrm{m})$ & - & 2.00 & - \\
\hline & & \multirow{2}{*}{$0<z<3$} & $\mathrm{e}_{\mathrm{v}}(\mathrm{m})$ & - & 0.3 & - \\
\hline & & & $\mathrm{L}_{\mathrm{R}}(\mathrm{m})$ & - & 3.21 & - \\
\hline \multirow{4}{*}{$\begin{array}{c}\text { A } \\
\text { Sol } 2(\mathrm{~J}) \\
+ \\
\text { Sol } 2(\mathrm{NH}) \\
\end{array}$} & \multirow{4}{*}{ GCR1 } & \multirow{2}{*}{$3<z<6$} & $\mathrm{e}_{\mathrm{v}}(\mathrm{m})$ & 0.3 & 0.3 & 100 \\
\hline & & & $\mathrm{L}_{\mathrm{R}}(\mathrm{m})$ & 2.95 & 2.00 & 68 \\
\hline & & \multirow{2}{*}{$0<z<3$} & $\mathrm{e}_{\mathrm{v}}(\mathrm{m})$ & 0.5 & 0.3 & 60 \\
\hline & & & $\mathrm{L}_{\mathrm{R}}(\mathrm{m})$ & 2.95 & 3.59 & 121 \\
\hline
\end{tabular}

PPR1 is the percentage of a parameter obtained by the method of $\mathrm{NH}$, for the same parameter obtained by the method of Jewell.

With the method of Jewell, the length of the reinforcement was not affected by the consideration of different geosynthetics. For this method, $L_{R}$ is determined from the overall and direct sliding stability. In the cases studied the overall stability was the most critical (depending only on the soil friction angle and the interstitial pressure).

For the method of $\mathrm{NH}$ the use of the geogrid GGR2 results in a LR smaller than for the GCR1. This results from the different mechanisms of mobilisation of the soil-geosynthetic interface strength.

The comparison of $L_{R}$ obtained by the two methods can only be performed for solution 2, as it is the one where the same geosynthetics were used as reinforcements for both methods. Thus, the length of the reinforcement obtained by the method of $\mathrm{NH}$ corresponds to $68 \%$ of one by the method of Jewell at the bottom of the wall $(3 \mathrm{~m}<\mathrm{z}<6 \mathrm{~m})$ and to $121 \%$ in the upper zone $(0 \mathrm{~m}<\mathrm{z}<3 \mathrm{~m})$. Therefore, for these cases, it seems that the method of Jewell is more conservative in the lower areas of the wall; and the opposite occurs in the upper zone. It may also be referred that these results may indicate that the method of $\mathrm{NH}$ offers a minor waste of reinforcement, as the length varies with the height of the wall. Nevertheless, such variation can originate difficulties during construction.

For both methods, it appears that, at the top of the wall, the length of the reinforcement is approximately equal to wall width (3.5 $\mathrm{m}$ on the top of the wall). 
With respect to the vertical spacing between reinforcement layers, $e_{v}$ obtained for granular soils (case A), the use of geosynthetics with different characteristics and types leads to differences in this parameter. In the various solutions studied for case $\mathrm{A}$, for the geogrids the $\mathrm{e}_{\mathrm{v}}$ is greater than for the case of the application of geocomposite GCR1. For GGR1 this was expected, as it has lower tensile strength.

The differences between the $e_{v}$ values obtained for the two methods considered, can only be discussed for solution 2, due to the reasons mentioned before. Comparing the values obtained, it is clear that for the bottom of the wall (3 $\mathrm{m}<\mathrm{z}<6 \mathrm{~m}) \mathrm{e}_{\mathrm{v}}$ is the same for both methods, but for the upper zone $(0 \mathrm{~m}<\mathrm{z}<3 \mathrm{~m})$ the parameter obtained by the method of $\mathrm{NH}$ corresponds to $60 \%$ of the necessary by using the method of Jewell. Once again and for the upper zone of the wall, it seems that the method of $\mathrm{NH}$ is more conservative than the method of Jewell, since it implies a greater density of reinforcements.

For a general comparison of the two methods used for granular soils, and for the cases studies considered, it is showed that the method of $\mathrm{NH}$ is more conservative in the determination of $\mathrm{e}_{\mathrm{v}}$. A possible explanation of such results can be associated with the consideration of the cohesive parcel in the strength of the soil in the design using $\mathrm{NH}$ method. As in this study the method was used for a granular soil, thus without cohesion, one can admit as a possibility that the contribution of this propriety is safeguarded by the reduction of $e_{v}$. Nevertheless, for obtaining the $L_{R}$ the most conservative method used is the method of Jewell.

Relatively to the results obtained when the wall is constituted by fine soil, the $L_{R}$ value obtained by the expeditious method described by Naughton (2009) is lower than the one obtained by the method of Jewell, as suggested in Table 9. There is no consistent relationship between the lengths obtained by both methods.

The LR results obtained as Naughton (2009) proposes only depend on the fine soil friction angle and the wall height. Therefore the results obtained for the two combination of fine soil parameters $\left(\mathrm{C}_{1}\right.$ and $\left.\mathrm{C}_{2}\right)$ considered are quite different. The length of reinforcement needed for case $\mathrm{B}_{\mathrm{C} 1}$ is only $41 \%$ of the value for $\mathrm{B}_{\mathrm{C} 2}$.

When comparing the $L_{R}$ values obtained for the two methods (Jewell (1996) and Naughton (2009)), the largest difference is obtained for case $\mathrm{B}_{\mathrm{C} 1}$, where the value for Naugthon (2009) is $75 \%$ of the same quantity determined using the method of Jewell. 
From Table 9 it is also clear that the vertical spacing of the reinforcements obtained with both methods is practically the same. This results from the maximum value referred by Naughton et al. (2001) of $0.5 \mathrm{~m}$.

Table 9 - Results obtained by the methods of internal design - fine soils.

\begin{tabular}{|c|c|c|c|c|c|c|}
\hline \multirow{2}{*}{$\begin{array}{l}\text { Case } \\
\text { study }\end{array}$} & \multirow{2}{*}{ Geosynthetics } & \multirow{2}{*}{$\mathrm{z}(\mathrm{m})$} & \multirow{2}{*}{ Parameter } & \multicolumn{2}{|c|}{ Design method } & \multirow{2}{*}{$\begin{array}{c}\text { PPR2 } \\
(\%)\end{array}$} \\
\hline & & & & Jewell & Naughton (2009) & \\
\hline \multirow{3}{*}{$\mathrm{B}_{\mathrm{C} 1}$} & \multirow{3}{*}{ GCR2 } & \multirow{3}{*}{$0<z<6$} & $\overline{\mathrm{e}_{\mathrm{v}}(\mathrm{m})}$ & 0.5 & 0.5 & 100 \\
\hline & & & $\mathrm{L}_{\mathrm{R}}(\mathrm{m})$ & 3.98 & 3.00 & 75 \\
\hline & & & $\theta\left(\times 10^{-7} \mathrm{~m}^{2} / \mathrm{s}\right)$ & - & 0.84 & - \\
\hline \multirow{6}{*}{$\mathrm{B}_{\mathrm{C} 2}$} & \multirow{6}{*}{ GCR2 } & \multirow{3}{*}{$3<z<6$} & $\mathrm{e}_{\mathrm{v}}(\mathrm{m})$ & 0.3 & 0.3 & 100 \\
\hline & & & $\mathrm{L}_{\mathrm{R}}(\mathrm{m})$ & 7.29 & 7.20 & 99 \\
\hline & & & $\theta\left(\times 10^{-7} \mathrm{~m}^{2} / \mathrm{s}\right)$ & - & 1.20 & - \\
\hline & & \multirow{3}{*}{$0<z<3$} & $\mathrm{e}_{\mathrm{v}}(\mathrm{m})$ & 0.6 & 0.5 & 83 \\
\hline & & & $\mathrm{L}_{\mathrm{R}}(\mathrm{m})$ & 7.29 & 7.20 & 99 \\
\hline & & & $\theta\left(\times 10^{-7} \mathrm{~m}^{2} / \mathrm{s}\right)$ & - & 0.84 & - \\
\hline
\end{tabular}

PPR2 is the percentage of a parameter obtained by the method of Naughton (2009), for the same parameter obtained by the method of Jewell.

It is also important to note that $\mathrm{e}_{\mathrm{v}}$ obtained by the method of Jewell results from an analysis in effective stresses, contrarily to what happens in Naughton et al. (2001), in which the conditions of design for this parameter correspond to a total stresses state. Thus, the method of Naughton et al. (2001) considers a maximum value for the vertical spacing between reinforcements, from which it becomes difficult to ensure the process, time and degree of appropriate consolidation of the layers of fill.

Regarding the comparison of results obtained for the two soil types, as expected, the values of $L_{R}$ are greater when the strength properties of the soil are worse, i.e., it s higher for fine soils. This happens because the strength of the soilreinforcement interface depends on the properties of these materials. So, for the same geosynthetics, a soil with lower resistant characteristics mobilizes lower resistance, per unit of length, of the reinforcement and, then, a higher $L_{R}$ is necessary to have the same resistance.

The spacing $\mathrm{e}_{\mathrm{v}}$ obtained by the method of Jewell is conditioned by the required and the available stresses on the reinforcement. Thus, the effect of soil properties is visible in the required stresses in the reinforcement. This is higher if the soil has lower resistance characteristics. As for the available stress in the reinforcement, this is conditioned by the resistance of the geosynthetics. 
Therefore, one can say that for lower resistant characteristics of the soil and of the geosynthetics, smaller $e_{v}$ are obtained, and then higher density of reinforcements is needed.

Another factor that may influence $L_{R}$ and $e_{v}$ values is the presence of water near the wall. Through the abacus of the method of Jewell it is shown that the greater the value of $r_{u}$ the greater the value of $L_{R}$. For $e_{v}$, the presence of water increases the required stress in the reinforcements (the existence of interstitial pressures raises the total stresses). So, for the same available stress, it is necessary to change (decreasing) the $e_{v}$ to ensure the stability of the structure, taking into account the presence of water.

To end this discussion, the results obtained in this study for profiles consisting of fine soil are compared with the results obtained by Naughton et al. (2001), described in Section 3.1, for the application example.

Comparing the values represented in Table 9 with the values listed in Table 7, from the example described in Naughton et al. (2001), it appears that the vertical spacing is equal for almost all situations, the exception being the lower part of the wall for case $\mathrm{B}_{\mathrm{C} 2}$ in which the spacing is smaller. This suggests that the maximum recommended value for this parameter is conservative for walls with dimensions of the same order of magnitude of ones in this study.

The other parameter that is necessary to discuss is the required transmissivity of the reinforcement to ensure its hydraulic function. From the results obtained, it appears that this parameter is substantially larger than the one obtained by Naughton et al. (2001).

Whereas the soil characteristics (in this study $\mathrm{c}_{\mathrm{v}}=5.2 \mathrm{~m}^{2} /$ years and $\mathrm{m}_{\mathrm{v}}=$ $4.13 \times 10^{-4} \mathrm{kPa}^{-1}$ and in the study of Naughton et al. (2001) $\mathrm{c}_{\mathrm{v}}$ range between 6 to $10 \mathrm{~m}^{2} /$ years and $\mathrm{m}_{\mathrm{v}}$ varies between $3 \times 10^{-4}$ and $5 \times 10^{-4} \mathrm{kPa}^{-1}$ ), the dimensions of the structure and the type of boundary at the base of the wall (impermeable boundary) are approximate in the two studies compared here. The difference obtained for the required transmissivity of geosynthetics can only be explained by the fact that in the case studied by Naugthon et al. (2001) an additional surface load was not considered, as used in the present study.

Thus, in the current study, the structure is subject to an additional load that can cause higher excesses of interstitial pressures during the construction process. 
Therefore, the required transmissivity of the reinforcement has to be consistently higher.

\subsection{Verification of external stability}

The verification of all the external failure mechanisms leads to a large set of results which are presented by Carlos (2009). In this paper it was considered relevant to include information of whether safety regarding such mechanism is verified. Nevertheless, in this section the results referring to the overall stability are presented in detail, due to some peculiar results that should be clarified.

A summary of the results from the analysis of the wall external stability is presented in Table 10. In the long-term, for effective stresses (ES), all cases studied are stable for the failure mechanisms considered. As expected, in the short term, when the minimum values of the safety factors occur, the situation is different. In fact, for total stresses (TS) the external stability can not be guaranteed without additional measures during the construction phase. The sliding at the base and the loss of overall stability may occur. Such measures are described later.

Table 10 - Results of the verification of the external stability.

\begin{tabular}{cccc}
\hline \multirow{2}{*}{ Case study } & Mechanisms of failure & \multicolumn{2}{c}{ Verify? } \\
\cline { 3 - 4 } & Failure by toppling & Effective stress (ES) & Total stress (TS) \\
\hline \multirow{2}{*}{$\mathrm{A}_{\mathrm{C} 1}$} & Failure by sliding at the base & Yes & Yes \\
& Bearing resistance failure & Yes & No \\
& Loss of overall stability & Yes & Yes \\
& Failure by toppling & Yes & No \\
$\mathrm{A}_{\mathrm{C} 2}$ & Failure by sliding at the base & Yes & No \\
& Bearing resistance failure & Yes & No \\
& Loss of overall stability & Yes & Yes \\
& Failure by toppling & Yes & Yes \\
$\mathrm{B}_{\mathrm{C} 1}$ & Failure by sliding at the base & Yes & No \\
& Bearing resistance failure & Yes & Yes \\
& Loss of overall stability & Yes & No \\
& Failure by toppling & Yes & Yes \\
$\mathrm{B}_{\mathrm{C} 2}$ & Failure by sliding at the base & Yes & No \\
& Bearing resistance failure & Yes & No \\
& Loss of overall stability & Yes & No \\
\hline
\end{tabular}

Furthermore, the most relevant failure mechanism for the cases studied corresponds to failure by sliding at the base. This mechanism may always occur for total stresses. On the contrary, the failure by toppling will not occur for the cases studied.

Finally, it is not possible to say that external failures are more likely to occur with one of the combination for the fine soil parameters. In fact, such problems 
were observed for both cases, which results in the necessity of using additional stabilising measures.

Table 11 shows the global safety factors for effective and total stress states for Case A solution 1 (method of Jewell). Similarly, Table 12 includes the global safety factors for effective and total stress states for case B, solution resulting from Naughton (2009). Case A solution 1 (method of Jewell) is more conservative as it leads to higher spacing between reinforcement layers.

Table 11 - Results of the overall stability for case A.

\begin{tabular}{|c|c|c|c|c|c|c|}
\hline $\begin{array}{l}\text { Case } \\
\text { study }\end{array}$ & $\begin{array}{c}\text { Stresses } \\
\text { state }\end{array}$ & Properties of soil & $\begin{array}{l}\text { Properties of } \\
\text { geosynthetics }\end{array}$ & Verification profile & FS & Verify? \\
\hline $\mathrm{A}_{\mathrm{C} 1}$ & & $\begin{array}{c}\text { Wall soil } \\
\gamma_{\mathrm{d}}=18 \mathrm{kN} / \mathrm{m}^{3} \\
\phi^{\prime}=33^{\circ} \\
c^{\prime}=0 \mathrm{kPa}\end{array}$ & $\begin{array}{c}0<\mathrm{H}<3 \mathrm{~m} \\
\mathrm{~F}_{\varepsilon}=48 \mathrm{kN} / \mathrm{m} \\
\mathrm{e}_{\mathrm{v}}=0.5 \mathrm{~m}\end{array}$ & & 3.4 & Yes \\
\hline $\begin{array}{c}\mathrm{A} \\
\mathrm{C} 1.1\end{array}$ & & $\begin{array}{c}\text { Foundation soil } \\
\begin{array}{c}\gamma_{\mathrm{sat}}=20 \mathrm{kN} / \mathrm{m}^{3} \\
\phi^{\prime}=34^{\circ} \\
c^{\prime}=7 \mathrm{kPa}\end{array}\end{array}$ & $\begin{array}{c}3<\mathrm{H}<6 \mathrm{~m} \\
\mathrm{~F}_{\varepsilon}=33 \mathrm{kN} / \mathrm{m} \\
\mathrm{e}_{\mathrm{v}}=0.6 \mathrm{~m}\end{array}$ & & 0.3 & No \\
\hline $\mathrm{A}_{\mathrm{C} 1}$ & TS & $\begin{array}{c}\text { Wall soil } \\
\gamma_{\mathrm{d}}=18 \mathrm{kN} / \mathrm{m}^{3} \\
\phi^{\prime}=33^{\circ} \\
\mathrm{c}^{\prime}=0 \mathrm{kPa} \\
\text { Foundation soil } \\
\gamma_{\mathrm{sat}}=20 \mathrm{kN} / \mathrm{m}^{3} \\
\mathrm{c}_{\mathrm{u}}=15 \mathrm{kPa}\end{array}$ & $\begin{array}{c}0<\mathrm{H}<3 \mathrm{~m} \\
\mathrm{~F}_{\varepsilon}=48 \mathrm{kN} / \mathrm{m} \\
\mathrm{e}_{\mathrm{v}}=0.5 \mathrm{~m} \\
3<\mathrm{H}<6 \mathrm{~m} \\
\mathrm{~F}_{\varepsilon}=33 \mathrm{kN} / \mathrm{m} \\
\mathrm{e}_{\mathrm{v}}=0.6 \mathrm{~m}\end{array}$ & & 0.8 & No \\
\hline $\mathrm{A}_{\mathrm{C} 2}$ & ES & $\begin{array}{c}\text { Wall soil } \\
\gamma_{\mathrm{d}}=18 \mathrm{kN} / \mathrm{m}^{3} \\
\phi^{\prime}=33^{\circ} \\
\mathrm{c}^{\prime}=0 \mathrm{kPa} \\
\text { Foundation soil } \\
\gamma_{\mathrm{sat}}=20 \mathrm{kN} / \mathrm{m}^{3} \\
\phi^{\prime}=20^{\circ} \\
\mathrm{c}^{\prime}=27 \mathrm{kPa}\end{array}$ & $\begin{array}{c}0<\mathrm{H}<3 \mathrm{~m} \\
\mathrm{~F}_{\varepsilon}=48 \mathrm{kN} / \mathrm{m} \\
\mathrm{e}_{\mathrm{v}}=0.5 \mathrm{~m} \\
3<\mathrm{H}<6 \mathrm{~m} \\
\mathrm{~F}_{\varepsilon}=33 \mathrm{kN} / \mathrm{m} \\
\mathrm{e}_{\mathrm{v}}=0.6 \mathrm{~m}\end{array}$ & & 3.3 & Yes \\
\hline $\mathrm{A}_{\mathrm{C} 2}$ & TS & $\begin{array}{c}\text { Wall soil } \\
\gamma_{\mathrm{d}}=18 \mathrm{kN} / \mathrm{m}^{3} \\
\phi '=33^{\circ} \\
\mathrm{c}^{\prime}=0 \mathrm{kPa} \\
\text { Foundation soil } \\
\gamma_{\mathrm{sat}}=20 \mathrm{kN} / \mathrm{m}^{3} \\
c_{\mathrm{u}}=25 \mathrm{kPa}\end{array}$ & $\begin{array}{c}0<\mathrm{H}<3 \mathrm{~m} \\
\mathrm{~F}_{\varepsilon}=48 \mathrm{kN} / \mathrm{m} \\
\mathrm{e}_{\mathrm{v}}=0.5 \mathrm{~m} \\
3<\mathrm{H}<6 \mathrm{~m} \\
\mathrm{~F}_{\varepsilon}=33 \mathrm{kN} / \mathrm{m} \\
\mathrm{e}_{\mathrm{v}}=0.6 \mathrm{~m}\end{array}$ & & 1.6 & Yes \\
\hline
\end{tabular}


From the values in Tables 11 and 12, it is possible to observe that the structure is stable when the soil is in effective stresses (long-term). On the contrary, this mechanism may happen in both cases A and B when the soil stress state is total (short-term). This is also visible in Table 10.

However, in Table 11 the critical failure surface is quite small and superficial (facing of the wall) and has a very low safety factor (case Ac1.1). Due to this surface it would not be possible to say that the wall is stable. However, in the numerical analyses performed using Slope/W, the effect of the envelope facing was not considered. Therefore, it is expected that the presence of the reinforcement is sufficient to overcome such situation.

As expected, from the failure surfaces illustrated in Tables 11 and 12 it is clear that, in most cases, the failure surface is not in the reinforced area. Therefore, the area of the base and of the wall foundation soil are critical for the wall overall stability. This leads to the conclusion that the stability of reinforced wall becomes almost exclusively dependent on the foundation soil of the structure.

Table 12 - Results of the overall stability for case B.

\begin{tabular}{|c|c|c|c|c|c|c|}
\hline $\begin{array}{l}\text { Case } \\
\text { study }\end{array}$ & $\begin{array}{c}\text { Stresses } \\
\text { state }\end{array}$ & $\begin{array}{c}\text { Properties of } \\
\text { soil }\end{array}$ & $\begin{array}{l}\text { Properties of } \\
\text { geosynthetics }\end{array}$ & Verification profile & FS & Verify? \\
\hline $\mathrm{B}_{\mathrm{C} 1}$ & $\mathrm{ES}$ & $\begin{array}{c}\text { Wall and } \\
\text { foundation soil } \\
\gamma_{\mathrm{sat}}=20 \mathrm{kN} / \mathrm{m}^{3} \\
\phi^{\prime}=34^{\circ} \\
c^{\prime}=7 \mathrm{kPa}\end{array}$ & $\begin{array}{c}\mathrm{F}_{\varepsilon}=50 \mathrm{kN} / \mathrm{m} \\
\mathrm{e}_{\mathrm{v}}=0.5 \mathrm{~m}\end{array}$ & & 1.5 & Yes \\
\hline $\mathrm{B}_{\mathrm{C} 1}$ & $\mathrm{TS}$ & $\begin{array}{c}\text { Wall and } \\
\text { foundation soil } \\
\gamma_{\mathrm{sat}}=20 \mathrm{kN} / \mathrm{m}^{3} \\
\mathrm{c}_{\mathrm{u}}=25 \mathrm{kPa}\end{array}$ & $\begin{array}{c}\mathrm{F}_{\varepsilon}=50 \mathrm{kN} / \mathrm{m} \\
\mathrm{e}_{\mathrm{v}}=0.5 \mathrm{~m}\end{array}$ & & 0.9 & No \\
\hline $\mathrm{B}_{\mathrm{C} 2}$ & ES & $\begin{array}{c}\text { Wall and } \\
\text { foundation soil } \\
\gamma_{\mathrm{sat}}=20 \mathrm{kN} / \mathrm{m}^{3} \\
\phi^{\prime}=20^{\circ} \\
c^{\prime}=27 \mathrm{kPa}\end{array}$ & $\begin{array}{c}0<\mathrm{H}<3 \mathrm{~m} \\
\mathrm{~F}_{\varepsilon}=50 \mathrm{kN} / \mathrm{m} \\
\mathrm{e}_{\mathrm{v}}=0,3 \mathrm{~m} \\
3<\mathrm{H}<6 \mathrm{~m} \\
\mathrm{~F}_{\varepsilon}=50 \mathrm{kN} / \mathrm{m} \\
\mathrm{e}_{\mathrm{v}}=0,5 \mathrm{~m}\end{array}$ & & 1.6 & Yes \\
\hline $\mathrm{B}_{\mathrm{C} 2}$ & TS & $\begin{array}{c}\text { Wall and } \\
\text { foundation soil } \\
\gamma_{\mathrm{sat}}=20 \mathrm{kN} / \mathrm{m}^{3} \\
\mathrm{c}_{\mathrm{u}}=15 \mathrm{kPa}\end{array}$ & $\begin{array}{c}0<\mathrm{H}<3 \mathrm{~m} \\
\mathrm{~F}_{\varepsilon}=50 \mathrm{kN} / \mathrm{m} \\
\mathrm{e}_{\mathrm{v}}=0,3 \mathrm{~m} \\
3<\mathrm{H}<6 \mathrm{~m} \\
\mathrm{~F}_{\varepsilon}=50 \mathrm{kN} / \mathrm{m} \\
\mathrm{e}_{\mathrm{v}}=0,5 \mathrm{~m}\end{array}$ & & 0.5 & No \\
\hline
\end{tabular}




\subsection{Profile construction}

In Fig 5 a generic profile of the proposed solutions for the saltpan walls of the Aveiro lagoon is shown. In this figure various layers of reinforcement with vertical spacing $\mathrm{e}_{\mathrm{v}}$ and length equal to width of the wall are represented.

As mentioned before, for the use of such walls, it is necessary to reduce their permeability, allowing the control of the water level inside the saltpans. This is relevant for the solutions using granular soils as fill material. More, to increase the lifetime of the geosynthetics, it can be wise to cover them (protecting them from weathering and other agents affecting their durability). Such protection can be achieved by including solutions for surface erosion control, for example, geocells filled with soil, to promote the growth of vegetation. These solutions are designated in Fig 5 as erosion control systems. This element should be considered in all the solutions studied. The erosion control products have not been designed.

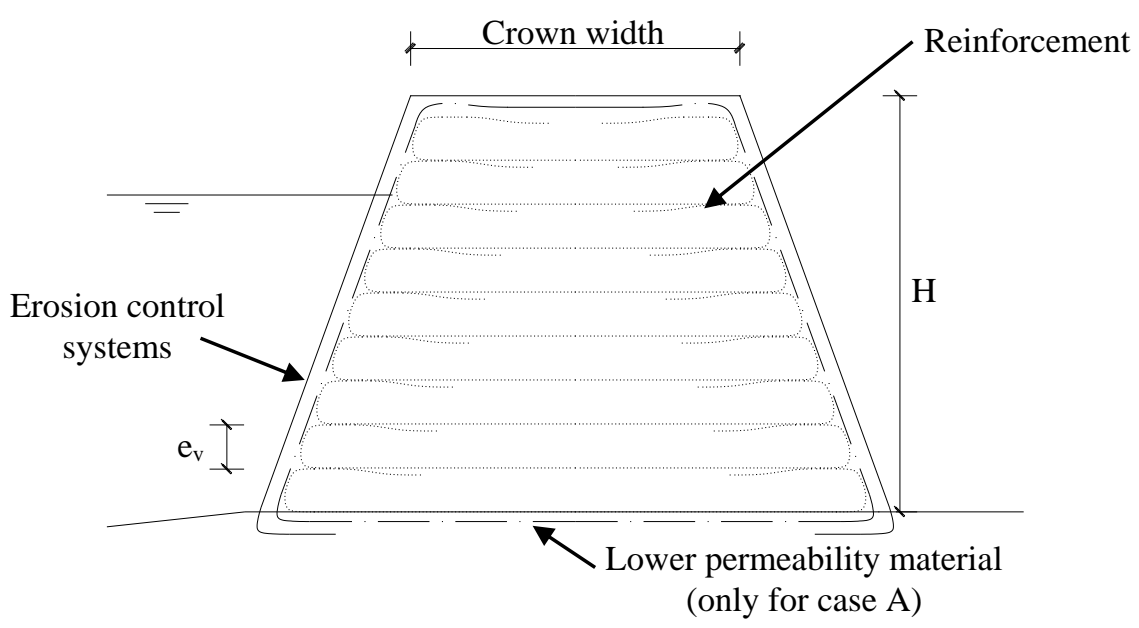

Fig 5 - Generic construction profile.

\subsection{Constructive process}

The main function of the structures studied is to protect the saltpans of the Aveiro lagoon, ensuring that they are not inundated by water from adjacent channels. Thus, the main constriction on its design and performance is the action of water. Therefore, it is necessary to take additional measures to control the effect caused by water, both during construction and during the lifetime of wall. Moreover, these measures combined with the construction of the wall structure, can be considered as the main stages of completing this type of work. 
The process of building the structure obeys to the standard wrap around process for wall/embankment design. However, there are differences in the construction process depending on the type of soil used. For example, in the construction of walls designed using fine soil as backfill material, it is important to define the duration of the waiting periods to allow the dissipation of the excesses of interstitial pressures.

For this study, these values can be found in Table 13, as well as the corresponding consolidation settlements, obtained by the method of Naughton et al. (2001). With these values, the contractor can schedule the construction, knowing the time between the completion of each layer and the beginning of the next and knowing the additional thickness to consider when building each layer in order to achieve the desired height of the wall at the end of the construction.

Table 13 - Time necessary for dissipation of excess of interstitial pressure $(\mathrm{T})$ and respective vertical settlements $\left(\delta_{\mathrm{v}}\right)$.

\begin{tabular}{cccccc}
\hline \multirow{2}{*}{ Case Study } & \multirow{2}{*}{$\mathrm{e}_{\mathrm{v}}(\mathrm{m})$} & \multicolumn{2}{c}{$\mathrm{T}$ (Hours) } & \multicolumn{2}{c}{$\delta_{\mathrm{v}}(\mathrm{mm})$} \\
\cline { 3 - 6 } & & One layer & Total & One layer & Total \\
\hline $\mathrm{B}_{\mathrm{C} 1}$ & 0.5 & 123 & 1477 & 37 & 446 \\
$\mathrm{~B}_{\mathrm{C} 2}$ & 0.5 & 123 & 1162 & 37 & 404 \\
\hline
\end{tabular}

For example for case study B, it appears that each layer must be built with an interval of 123 hours ( \pm 5 days) and that their thickness should be increased by an additional $37 \mathrm{~mm}$. Over the entire wall, the total time of pauses between the construction layers of the embankment should not be less than 1477 hours $( \pm 62$ days) and the additional total thickness is of $446 \mathrm{~mm}$.

With respect to the walls made of granular soils and after analysing the results obtained for the verification of the external failure mechanisms of the wall, it could be important to consider pauses in the construction process. Such analysis has not been done in the present paper.

The use of waterproofing systems of the wall has already been mentioned and should be clarified. The use of granular materials as backfill may result in stability problems induced by water and tidal action. Thus, besides the necessity of avoiding the entrance of water to the saltpans, these mechanisms must be avoided to prevent erosion. 
As previously stated, sealing the wall, for example by using geosynthetics (geomembranes, or geosynthetic clay liners) or the local fine soils is a possible solution.

For the solutions proposed where the backfill material is a fine soil, the low permeability of the soil results in a fluid barrier, thus the solution with geosynthetics is not necessary. However, the implementation of other solutions on the face of the wall to prevent erosion of that surface can be useful.

\section{CONCLUSIONS}

The conclusions that can be drawn from this study are essentially related to: the internal design methods (the number of existing methods, the difficulty of adapting these methods to conditions different from those considered in their development, their limitations, the development of new methods and the results obtained) and the verification of external stability (the comparison of the behaviour of reinforced and non reinforced wall/ and the differences caused by the type of stress state in the soil).

Relatively to the internal design, the number of methods found for structures such as the walls of the Aveiro lagoon is different, depending on the type of constituent soil, being the bibliography fairly comprehensive for granular soils, but limited for fine soils.

Also for the design methods, for fine soils, it was showed that the method found only considers the design of the drainage features that are necessary for the reinforcements, to ensure that a significant part of the consolidation of the fine soil occurs. So, it is only possible to do an analysis of the behaviour of the wall in the long-term, i.e., in effective stresses. Regarding the tensile strength of the reinforcements this method is very expeditious. Indeed, the authors of the method only suggest the choice and verification of its characteristics in an interactive way, until there is stability of the reinforced wall system, making it dependent on the user's experience.

It should be also noted that the methods found were developed for single slopes, not considering the interaction effect between two adjacent slopes, as in the cases studied.

Therefore, this study has tried to adapt the method of Jewell for the design of reinforcements for fine soils. From this adaptation it has been found that as it was 
developed for granular soils, its use with a fine soil (with cohesion), is conservative as does not consider that resistance component. Then, the results are conditioned by this factor.

As for the limitations of the methods of design: for the method of Jewell its main limitation is the application to granular soils only. This method is fairly divulged and of generalised application. Then, it is reliable, albeit conservative.

The main constraints of the method of Naughton et al. (2001) are related to the fact that the design of reinforcements is highly empirical and that it has been developed for the application of a specific type of geosynthetics, taking into account constants that only apply to these materials in the design process.

The main limitation of the method of $\mathrm{NH}$ is related to the factors used in reducing the resistant capacity of the geosynthetics. The method provides specific factors not allowing the use of factors suggested by the manufacturers that, theoretically, can be more reliable for each specific type of geosynthetics. More, such factors are quite conservative.

Then, it is concluded that, for the design of reinforcements of fine soils with geosynthetics it is necessary to develop new methods of design, preferably analytical, that consider the design of reinforcements for the various functions they have to fulfil.

For the results obtained, it can be concluded that they rely on simplifications and adjustments done during their use in design. Indeed, during those simplifications it was tried to ensure that they were always conservative. However, it is possible that sometimes they are too conservative, causing the increase of material waste and of costs associated to the construction of such solutions. In spite of that, within the limitations that this study shows, one can say that the results are within the expected range and solutions normally used in soil reinforcement.

Another conclusion that can be drawn is that sometimes the design process results in excessive values, as for the length of reinforcement. It was observed that sometimes it was impossible to place the reinforcements in the wall, as their length is larger than the available width of the wall. However, when performing external checks and assuming that the length of the reinforcement was only the width of the wall (maximum length possible) it was found that the wall was stable. Thus, it was concluded that is possible to reduce the $\mathrm{L}_{\mathrm{R}}$, by carrying out, in 
addition to the methods of internal design, the verification of external stability considering the soil-geosynthetic interface strength in such analysis. Note that these findings, once again, reinforce the idea that the methods considered are quite conservative.

The most conditioning factor for the external stability analyses is the stress state of the soil. In fact, for total stresses (short-term) the external stability of the walls was not always ensured. The adoption of additional stability measures is necessary.

Finally, it was found that the reinforcement with geosynthetics of the walls of the saltpans of the Aveiro lagoon is a very comprehensive field of study and still poorly developed.

\section{Symbology}

$\begin{array}{ll}\text { ATM } & \text { Atmospheric effects } \\ \text { BIO+CHE } & \text { Biological and chemical degradation } \\ c^{\prime} & \text { Cohesion in terms of effective stress } \\ c_{u} & \text { Undrained strength } \\ c_{v} & \text { Coefficient of vertical consolidation } \\ \text { C } & \text { Constant } \\ \text { CAL } & \text { Complex Alluvium Sludges } \\ \text { CR } & \text { Creep } \\ \text { C1 } & \text { Combination of fine soil parameters number 1 } \\ \text { C2 } & \text { Combination of fine soil parameters number 2 } \\ \text { DDI } & \text { Damage during installation } \\ \mathrm{e}_{v} & \text { Vertical spacing between reinforcement layers } \\ \text { E }_{p w p} & \text { Interstitial pressure generated by the construction of an embankment layer on a pre- } \\ & \text { existing layer } \\ \text { EQU } & \text { Loss of equilibrium of the structure or the ground } \\ \text { ES } & \text { Effective stresses } \\ F_{c J} & \text { Design tensile strength obtained by the method of Jewell (1996) } \\ F_{c N H} & \text { Ddesign tensile strength obtained by the method of the Nordic Handbook } \\ F_{k} & \text { Characteristic tensile strength of reinforcements } \\ F_{u l t} & \text { Ultimate tensile strength } \\ F_{\text {Diss }} & \text { Safety factor applied to the time of dissipation } \\ \text { GCR1 } & \text { Geocomposite number 1 } \\ \text { GCR2 } & \text { Geocomposite number 2 } \\ \text { GGR1 } & \text { Uniaxial Geogrid number 1 } \\ \text { GGR2 } & \text { Uniaxial Geogrid number 2 } \\ \end{array}$




\begin{tabular}{|c|c|}
\hline GEO & Collapse or excessive deformation of the ground \\
\hline $\mathrm{h}$ & Height of each layer \\
\hline $\mathrm{H}$ & Height of the wall \\
\hline $\mathrm{L}_{\mathrm{R}}$ & Length of the reinforcement \\
\hline $\mathrm{m}_{\mathrm{v}}$ & Coefficient of volume compressibility \\
\hline $\mathrm{n}$ & Number of layers constructed \\
\hline $\mathrm{qQ}_{\mathrm{Q}}$ & Surcharge caused by the construction process \\
\hline $\mathrm{r}_{\mathrm{u}}$ & Interstitial pressure parameter \\
\hline $\mathrm{RF}_{\text {total }}$ & Total reduction factor \\
\hline RF & Reduction factor \\
\hline $\mathrm{RF}_{\mathrm{ATM}}$ & Reduction factor for atmospheric effects \\
\hline $\mathrm{RF}_{\mathrm{DDI}}$ & Reduction factor for damage during installation in situ \\
\hline $\mathrm{RF}_{\mathrm{FLU}}$ & Reduction factor for the effects of creep in the reinforcement \\
\hline STR & Internal collapse or excessive deformation of the structure or structural elements \\
\hline $\mathrm{T}$ & Time required to dissipate the excesses of interstitial pressure generated \\
\hline TS & Total stresses \\
\hline $\mathrm{u}$ & Interstitial pressure \\
\hline $\mathrm{V}$ & Volume of water dissipated \\
\hline $\mathrm{z}$ & Depth measured from the top of the wall to a point in study \\
\hline$\beta$ & Tilt the face of the structure from the horizontal \\
\hline$\delta_{\mathrm{v}}$ & Settlement \\
\hline$\phi^{\prime}$ & Soil friction angle in terms of effective stresses \\
\hline$\gamma$ & Unit weight of soil \\
\hline$\gamma_{\mathrm{M}}$ & Partial safety factor for the parameters of soil \\
\hline$\eta$ & Conversion factor \\
\hline$\eta_{1}$ & Conversion factor of creep \\
\hline$\eta_{2}$ & Conversion factor for the installation damage \\
\hline$\eta_{3}$ & Conversion factor for the biological and chemical degradation \\
\hline$\theta$ & Transmissivity \\
\hline
\end{tabular}

\section{ACKNOWLEDGEMENTS}

The authors acknowledge the support of FCT (Fundação para a Ciência e a Tecnologia), Research Project PTDC/ECM/65589/2006, Research Project PTDC/ECM/099087/2008 - FCOMP-01-0124FEDER-009724 and Research Project PTDC/ECM/100975/2008 - FCOMP-01-0124-FEDER009750 . 


\section{REFERENCES}

Allen, T. M. and Bathurst, R. J. (2003). "Prediction of reinforcement loads in reinforced soil walls". Washington State Department of Transportation and US Department of Transportation, Washington, USA, p 363.

Athanasopoulos, G. A. (1996). "Experimental investigation of shearing behaviour at cohesive soilgeotextile. Earth Reinforcement, Edited by Ochiai, Yasufuku e Omine, Balkema, pp9-12.

Berg, R. R.; Christopher, B. R. and Samtani, N. C. (2009). "Design of Mechanically Stabilized Earth Walls and Reinforced Soil Slopes". U.S. Department of Transportation, Federal Highway Administration, Washington DC, FHWA NHI-09-083 and FHWA GEC 011, p668.

Bergado, D. T.; Macatol, K. C.; Amin, N. U.; Chai, J. C. and Alfaro, M. C. (1993). "Interaction of lateritic soil and steel grid reinforcement". Canadian Geot. Journal, Vol. 30, №. 2, pp376384.

Bonito, F. A. B. (2008). "Rheology of sludge and other recent sediments of Aveiro lagoon". Ph.D. thesis in Civil Engineering. University of Aveiro, Aveiro. p422 (In Portuguese).

Carlos, D. M. (2009). "Reinforcement with geosynthetics of walls of the saltpans of the Aveiro lagoon". Master's thesis in Civil Engineering. University of Aveiro, Aveiro. p171 (In Portuguese).

Chang, D. T-T, Hung, F-Y, Sun, T-S (1996). "Laboratory study and numerical analysis for pullout behaviours of geogrids confined by weathered mudstone and sandy soil". Geosynthetics: Applications, Design and Construction, Edition of De Groot, Den Hoedt e Termaat, Balkema, Rotterdam, pp217-224.

Christopher, B. R. (2010). "USA design guidelines for geosynthetic reinforced soil walls, slopes and embankments". Proceedings of the 9th International Conference on Geosynthetics, Guarujá, Brazil, pp237-241.

Clancy, J. and Naughton, P. J. (2008). "Design of steep slopes using fine grained fills and novel multifunctional geocompósitos". Proceedings of the Fourth European Conference of Geosynthetics, Edinburgh, Scotland, CD-ROM, Paper number 131.

Corbet, S. P. and Horgan, G. (2010). "Introduction to international codes for reinforced soil design". Proceedings of the 9th International Conference on Geosynthetics, Guarujá, Brazil, pp225-231.

Elias, V.; Christopher, B. R. and Berg, R. R. (2001). "Mechanically Stabilized Earth Walls and Reinforced Soil Slopes, Design and Construction Guidelines". U.S. Department of Transportation, Federal Highway Administration, Washington DC, FHWA-NHI-00-043, p418.

Fleming, I. R.; Sharma, J. S. and Jogi, M. B. (2006). "Shear strength of geomembrane-soil interface under unsaturated conditions". Geotextiles and Geomembranes, Elsevier, Vol. 24, $\mathrm{N}^{\circ} .5$, pp274-284.

Gomes, L. M. F. (1992). "Geotechnical zoning from urban and suburban area of Aveiro". Ph.D. thesis in Engineering Geology. University of Aveiro. Vol 1, p531 (In Portuguese).

Jewell, R. A. (1996). "Soil Reinforcement with geotextiles". Special Publication 123 CIRIA. p332. 
Kempton, G. T.; Jones, C. J. F. P.; Jewell, R. A. and Naughton, P. J. (2000). "Construction of slopes using cohesive fills and a new innovative geosynthetic material". Proceedings of the 2nd European Conference on Geosynthetics, Bologna, Italy, Vol. 2, pp825-828.

Khedkar, M. S. and Mandal, J. N. (2009). "Pullout behavior of cellular reinforcements". Geotextiles and Geomembranes, Elsevier, Vol. 27, N. 4, pp262-271.

Liu, C. N.; Ho, Y. H. and Huang, J. W. (2009). "Large scale direct shear tests of soil/PET-yarn geogrid interfaces". Geotextiles and Geomembranes, Elsevier, Vol. 27, №. 1, pp19-30.

Moraci, N. and Cardile, G. (2009). "Influence of cyclic tensile loading on pullout resistance of geogrids embedded in a compacted granular soil". Geotextiles and Geomembranes, Elsevier, Vol. 27, No. 6, pp475-487.

Naughton, P. J. (2009). Personal communication (e-mail 19/05/2009).

Naughton, P. J.; Jewell, R. A. and Kempton, G. T. (2001). "The design of steep slopes constructed from cohesive fills and a geogrid". Landmarks in Earth reinforcement, IS Kyushu, Japan.

O'Kelly, B. C. and Naughton, P. J. (2008). On the interface shear resistance of a novel geogrid with in-plane drainage capability. Geotextiles and Geomembranes, Elsevier, Vol. 26, No. 4, pp357-362.

Pereira, C. and Coelho, C. (2007). "Walls of the saltpan marines of Aveiro". Earth in Seminar 2007, Proceedings of the V Seminar on Earth Architecture in Portugal, Aveiro, pp. 108-111, ISBN: 978-972-8479-49-7 (in Portuguese).

Pitanga, H. N.; Gourc, J. P. and Vilar, O. M. (2009). "Interface shear strength of geosynthetics: Evaluation and analysis of inclined plane tests". Geotextiles and Geomembranes, Elsevier, Vol. 27, No. 6, pp435-446.

Rogbeck, Y.; Alén, C.; Franzén, G.; Kjeld, A.; Odén, K.; Rathmayer, H.; Want, A. and Oiseth, E. (2002). "Nordic Handbook - Reinforced soils and fills". Nordic Geosynthetic Group (NGG), p203 (draft version de 20/12/2002).

Sieira, A. C.; Gerscovich, D. and Sayão, A. (2009). "Displacement and load transfer mechanisms of geogrids under pullout condition”. Geotextiles and Geomembranes, Elsevier, Vol. 27, №. 4, pp241-253.

SLOPE/W (2007). "Stability Modeling with SLOPE/W 2007 - An Engineering Methodology". GEO-SLOPE International Ltd, Calgary, Alberta, Canada, Second Edition, p344.

Yin, G.; Wei, Z.; Wang, J. G.; Wan, L. and Shean, L. (2008). "Interaction characteristics of geosynthetics with fine tailings in pullout test”. Geosynthetics International, Thomas Telford Vol. 15, No. 6, pp428-436.

\section{Standards}

AASHTO (2002). "Standard Specifications for Highway Bridges". 17th Edition, American Association of State Highway and Transportation Officials, Washington, D.C.

AASHTO (2007). "LRFD Bridge Design Specifications”. 4th Edition with 2008 and 2009 Interim Revisions. American Association of State Highway and Transportation Officials, Washington, D.C. 
BS 8006:-1: 2009. Code of Practice for Strengthened/reinforced soils and fills, Public Draft for Comment, BSi London 2009.

DIN 1054:2005-01. Baugrund; Sicherheitsnachweise im Erdund Grundbau; Deutsches Institut für Normung, Berlin.

EN 1997-1: 2004. Eurocode 7: Geotechnical design - Part 1: General rules.

ISO/TR 20432:2007 - Guidelines for the determination of the long-term strength of geosynthetics for soil reinforcement. 